\title{
EDITORIAL
}

\section{TRIBUTE TO THE "FATHER" OF EXPERIMENTAL MICROSURGERY, PROFESSOR SUN LEE (1920-2015)}

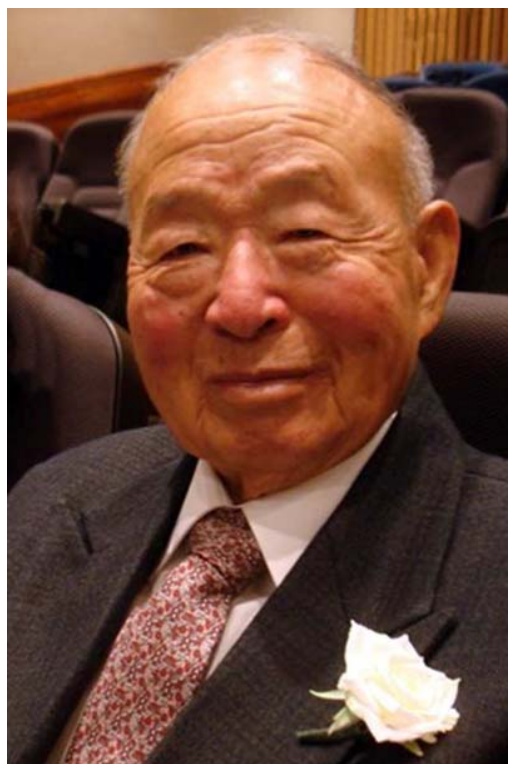

Professor Sun Lee (1920-2015) (permitted for publication by Mrs. Sun Lee)

Professor Sun Lee died peacefully on October 4, 2015 at his home in La Jolla, California.

Sil Heung Lee was born in Kangwondo Providence, Korea, in 1920. He graduated from the Seoul National University School of Medicine, then became a US citizen in 1950 and changed his name to Sun Lee. In the United

${ }^{*}$ Correspondence to: Norbert Nemeth, M.D., Ph.D., Department of Operative Techniques and Surgical Research, Faculty of Medicine, University of Debrecen, Debrecen, Hungary. E-mail: nemeth@med.unideb.hu

Received 11 November 2015; Accepted 24 November 2015

Published online 00 Month 2015 in Wiley Online Library (wileyonlinelibrary.com). DOI: 10.1002/micr.30015
States, he received postgraduate education at the St. Francis Hospital, Pittsburgh, in 1955. He joined Professor Bernard Fisher at the University of Pittsburgh. In 1968, Professor Frank Dixon invited him to the Scripps Clinic in La Jolla, joining the University of California Medical School. He founded the San Diego Microsurgical Institute. After the retirement in 1985, Sun Lee still possessed academic exchange with the University and the Scripps. He directed research on consecutive organ transplant studies at San Diego Microsurgical Institute till his age of 90.

Sun Lee was a great pioneer in microsurgery. His porto-caval shunt operation in the rat was the first published procedure initiating the development of experimental microsurgery. The end-to-side porto-caval shunt technique in the rat was invented and perfected in 1957/ 1958 and published in 1961. It was the beginning of the experimental microsurgery and opened the way to perform various organ and tissue transplantation procedures in rats and mice using advanced microsurgical techniques. Later Professor Sun Lee developed and refined numerous fundamental organ transplantation models in rodents: kidney (1961 and 1965), liver (1966), spleen (1969), heart-lung (1970), testicle (1970), pancreaticoduodenal transplant (1971), stomach (1972), ovarium (1975), porto-caval and arterio-venous shunts (1961 and 1962), among other techniques. Just like Alexis Carrel (Nobel Prize in 1912) who was a pioneer in vascular surgery with his triangular technique, Professor Sun Lee has created the basics of the experimental microsurgery for systematic organ transplantation research. These techniques and models served as the basis for transplantationrelated research on organ regeneration, organ and tissue preservation, ischemia-reperfusion, also developing techniques for microvascular anastomoses, and for transplantation immunology (rejection, immunosuppression, and 
tolerance induction). The usage of these experimental models was fundamental for the currently known and clinically used immunosuppressive therapies.

He was granted numerous awards and merits, just to mention the Interstate Medical Society Award (1959), the Korean Surgical Society Award-Key (Gold) (1975), the Lombard Surgical Society Gold Medal (1974), the Madrid University Gold Plate Award (1977), the International Microsurgical Society Gold Medal Award (1978), the US Minister of Health Silver Medal Award (1986), the Hua Shan Hospital Emblem Award (Shanghai) (1981), the Valmontone Hospital, Roma, Italy-Gold Medal Awards (1977 and 1978), the Hallym University Award-Gold Key (1980), the Catania University Bronze Medal Award (1983), the Italian Microsurgical Award, Alpus Congress-Gold Medal (1977), the Chungnam National University-Gold Turtle Award (1987), the Nihon University Japan-Gold Medal Award (Tanaka) (1989), and the Certificate of Merit, University of Debrecen (2009).

Professor Sun Lee has always supported the international relations, and taken care on microsurgeons from North and South America, Europe, Asia, and Africa, transferring microsurgical techniques into clinical practice (especially in vascular, hepatobiliary, and pancreatic surgery). He traveled to more than 40 countries, training and mentoring countless scholars and surgeons. He is the founder of the International Society for Experimental Microsurgery (ISEM).
Toward the University of Debrecen (Hungary), he also paid special attention in the last decade, donating instruments and scientific documents. Professors Istvan Furka and Iren Miko, my mentors, former heads of the department have established the Sun Lee Microsurgical Museum at our department, and a permanent exhibition in the University Medical History Collection. Professor Sun Lee received a Certificate of Merit from the Rector of the University of Debrecen in 2009.

His fond attention toward young generations was exceptional. (Personally I am also very grateful for his confidence and encouraging, supportive attention toward my work in the ISEM.) He was always open to others. His smiling and respectful personality irradiated harmony, knowledge, acceptance, fond care, mentorship, fathernity, guidance, like a real great man, great scientist, teacher, and father.

We all who had the privilege to know him, to meet him, will miss very much. We will preserve his memory in our hearts and in our activity!

NORBERT NEMETH, M.D., Ph.D.

President of the International Society for Experimental Microsurgery

Head of Department of Operative Techniques and

Surgical Research

Faculty of Medicine

University of Debrecen

Debrecen, Hungary 